\title{
Roda de conversa: metodologia na produção de narrativas sobre permanência na universidade ${ }^{1}$
}

\author{
Flávia Marinho Lisbôa*
}

\section{Introdução}

Este trabalho apresenta a roda de conversa como principal metodologia adotada em pesquisa de doutorado desenvolvida com estudantes indígenas Gavião dos grupos Parkatêjê, Akrátikatêjêe Kyikatêjê, graduandos na Universidade Federal do Sul e Sudeste do Pará (Unifesspa). O intuito da pesquisa foi compreender as implicaçôes para a permanência desses alunos na universidade e a roda de conversa surgiu como a alternativa metodológica mais pertinente na busca por uma forma de diálogo que atraísse e fizesse falar esses discentes, experiência a qual detalhamos neste artigo.

Ao longo do processo de busca de dados para a pesquisa, as rodas de conversa se revelaram uma metodologia válida náo apenas para viabilizar os enunciados necessários para a análise da problemática de pesquisa como também uma ferramenta importante para reflexão e construção política da forma-sujeito dos alunos. Nas vivências expressadas nas rodas, foi possível perceber a narrativa comum que eles partilhavam sobre as experiências do racismo institucional

1 Este artigo reproduz parte do capítulo da metodologia de pesquisa de doutorado da autora, intitulada "Língua como linha de força do Dispositivo Colonial: os Gavião entre a aldeia e a universidade", defendida no Programa de Pós-Graduação em Letras da Universidade Federal do Pará (UFPA). A pesquisa recebeu bolsa Capes pelo período de seis meses.

* Docente da Universidade Federal Rural da Amazônia (UFRA), Campus de Paragominas-PA. Graduada em Letras, também possui doutorado na mesma área, com ênfase em Estudos Linguísticos, pela Universidade Federal do Pará (UFPA). E-mail: flaviamlisboa@gmail.com. 
peculiar à educação superior no Brasil, compreendendo-as não como problemas isolados e individualizados. Ao contrário, as angústias partilhadas nas rodas se evidenciaram como um problema social e coletivo, tomando corpo, assim, uma narrativa denunciadora da homogeneidade universitária, que materializa a colonialidade estruturante na sociedade como um todo.

Para o detalhamento dessa experiência, organizamos este artigo em quatro tópicos: o primeiro faz uma suscinta apresentação do povo Gavião, relacionando ao final essa história à demanda do ensino superior; o segundo expóe compreensóes sobre a roda de conversa na sua tomada como metodologia de pesquisa; o terceiro é onde mostramos os resultados da experiência com os alunos e, por fim, consideramos as idiossincrasias e benefícios da adoção da roda de conversa como metodologia na pesquisa em questão.

\section{Alunos Gavião: história, território e necessidade de formação acadêmica}

Apesar da intensificação da vivência sistemática com a sociedade regional, especialmente a partir da implantação de políticas para "integração" da Amazônia (meados do século XX), o povo Gavião ainda mantêm seu modo de vida pautado em fundamentos cosmológicos dos Timbira, ${ }^{2}$ tanto nas práticas cotidianas $\mathrm{e}$ como em momentos específicos que evidenciam sua ligação com os sentidos que movem suas existências. Apesar de todas as influências não-indígenas, a vida na aldeia ainda é o espaço onde as práticas tradicionais são fortalecidas, porém, não numa perspectiva estereotipada, mas na atualização que exige o contato sistemático com o restante da populaçáo nacional. Nisso, a Terra Indígena Mãe Maria, onde vivem, constitui-se como o espaço da negociação intercultural, o espaço heterotópico, buscando as lentes de Foucault, quando diz que há

[...] lugares reais, lugares efetivos, lugares que são delineados na própria instituição da sociedade e que são espécies de contra posicionamentos, espécies de utopias efetivamente realizadas nas quais os posicionamentos reais, todos os outros posicionamentos reais que se podem encontrar no

2 O povo Gavião foi inicialmente instituído por três diferentes grupos de origem Timbira, os Parkatêjê, os Kyikatêjê e os Akrãtikatêjê, que se dividiram no início do século XX, passando a ocupar uma parte do território do Maranhão e a região sudeste do estado do Pará (Ferraz, 1998), especificamente onde hoje estão os municípios de Tucuruí e Itupiranga. Em 1966, eles começaram a ser reunidos na Terra Indígena Mãe Maria pela Fundação Nacional do Índio (Funai), processo iniciado com os Parkatêjê e que termina em 1968, com a chegada dos outros dois grupos. 
interior da cultura estão ao mesmo tempo representados, contestados e invertidos, espécies de lugares que estão fora de todos os lugares, embora eles sejam efetivamente localizáveis. Esses lugares, por serem absolutamente diferentes de todos os posicionamentos que eles refletem e dos quais eles falam, eu os chamarei, em oposição às utopias, de heterotopias. (Foucault, 2005, p. 415).

Essa percepção heterotópica acompanha todo o contato dos povos indígenas com as frentes da colonização, desde o início desse processo. Esses alunos e alunas indígenas vivem essa heterotopia em seus corpos, no dia a dia desse contato. Uma das alunas interlocutoras dessa pesquisa explicou como a aldeia é um espaço regido por outro tempo e modos de relaçóes interpessoais:

Nós estamos aqui e como é a vida do índio aqui? você tem que comer, dormir, brincar. Agora, aqui não. O dia a dia é correria, lá fora, é diferente daqui. Aqui é tranquilo, mas lá? é cada um passando o pé no outro. (Aluna do Curso de Pedagogia, 2017).

Assim, podemos considerar a Terra Indígena Mãe Maria como o lugar da negociação Timbira-Gaviáo desde os anos 1960, quando lá foram reunidos os Parkatêjê, os Akrătikatêjêe e os Kyikatêjê. Nessa perspectiva, o território inicialmente simbolizaria um aprisionamento dos grupos pela limitação e resignação diante da perda de suas florestas para a populaçáo regional, mas, por outro lado, também significou o fortalecimento e a repopulação depois de beirarem à extinção, possibilitando assim não só a sobrevivência dos grupos Timbira, mas também a retomada de suas práticas cosmológicas (Ferraz, 1998). Porém, a luta em defesa do território não cessou, pois a Terra Indígena (TI), mesmo como reserva demarcada e destinada para esse povo desde 1943, nunca deixou de ser fortemente cobiçada pelo kupen ${ }^{3}$

[...] por causa dos vultuosos e impactantes empreendimentos na Amazônia como a Usina Hidrelétrica de Tucuruí e seus linhôes de transmissão elétrica, a grande mina de Carajás e a Estrada de Ferro Carajás, a construção de novas rodovias, a imigração maciça [...], a ação de madeireiros [...]. Esses índios, assim como os Gavióes-Parkatêjê, Guajajara, Urubu-Kaapor, Guajá, Suruí, Zoró, Nambiquara, entre outros, iriam sofrer pressóes de todos os lados. (Gomes, 2017, p. 109).

3 Esse termo é utilizado pelos indígenas Gavião para se referirem à pessoa não-indígena. 
A TI Mãe Maria localiza-se no sudeste do estado do Pará, na Amazônia Oriental. Os processos de colonização dessa região seguiram a história dos ditames autoritários do europeu na América Latina, mas foram intensamente verticalizados no século XX, já agenciados pelo Estado brasileiro e pelas empresas transnacionais. Naturalmente, as frentes econômicas e culturais as quais foram expostos os Gavióes particularizam a história desse povo e ao mesmo tempo em que suas narrativas traduzem a globalização de nossos dias, também exibe seus saberes locais, suas particularidades.

A TI Mãe Maria possui 62.488 hectares e fica na margem direita do rio Tocantins, situada no município de Bom Jesus do Tocantins, a $30 \mathrm{~km}$ da cidade de Marabá (como podemos ver no mapa abaixo), proximidade essa que justifica a intensa relaçáo do grupo com o município e, consequentemente, o grande número de alunos Gaviáo presentes nos campi da Unifesspa nessa cidade. Prova disso é que o número de indígenas da etnia Gavião na Unifesspa é substancialmente maior que o das demais etnias da região. Marabá também atrai todas as demais populaçóes (indígenas ou não) ao seu redor, por ser o mais importante polo comercial e institucional da regiáo.

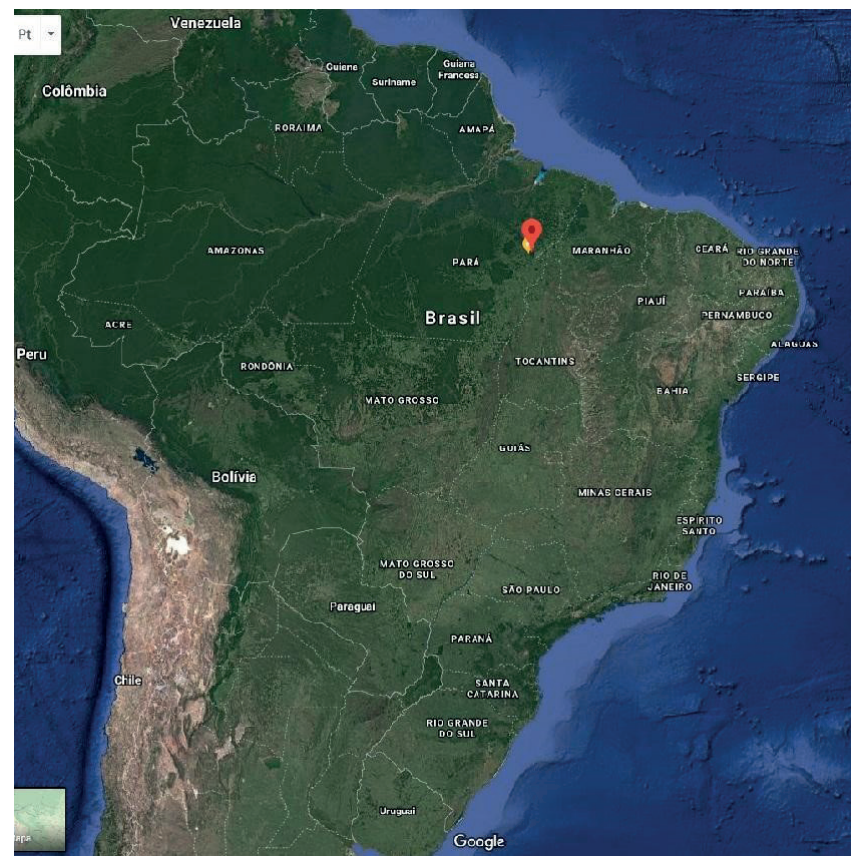

Figura 1 - Localização da Terra Indígena Mãe Maria no mapa do Brasil (Fonte: Google Maps) 


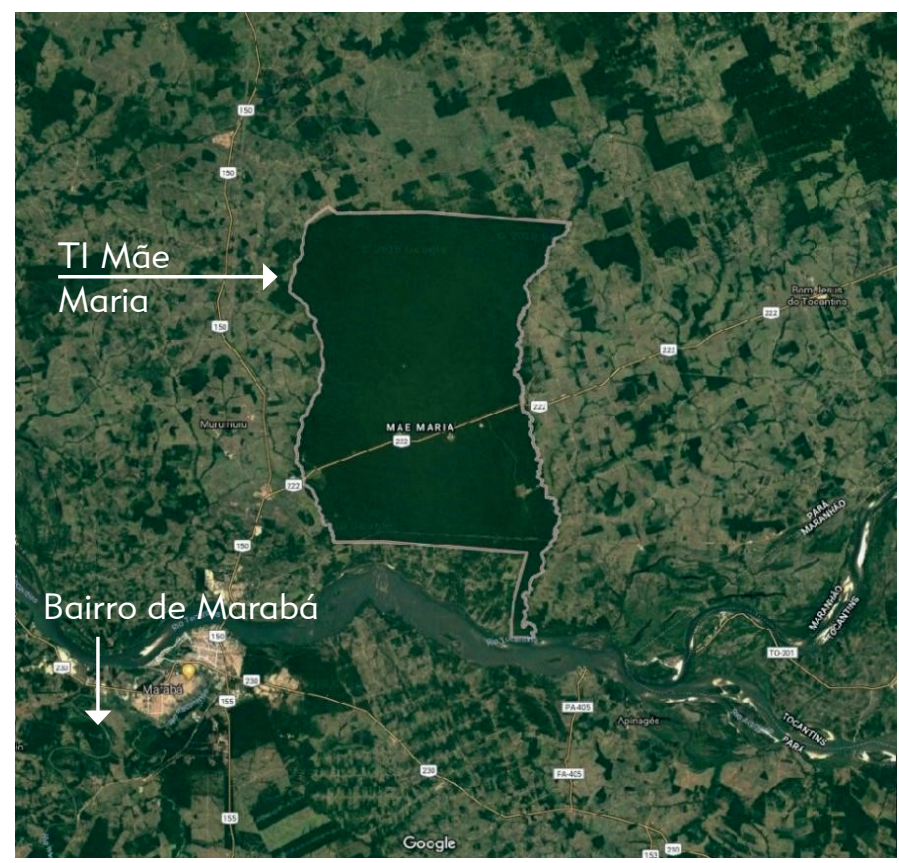

Figura 2 - Terra Indígena Mãe Maria

(Fonte: Google Maps)

Batizados pela população regional como "Gaviāo", diversos autores, cronistas e naturalistas começaram a se referir dessa forma aos grupos indígenas Timbira que viviam às margens do curso médio do rio Tocantins. O etnômio "Gaviōes" teria sido conferido para designar a resistência desses indígenas à dominação externa, baseando-se no significado do termo português "ave de rapina". Na segunda metade do século XX esses indígenas estavam sendo sistematicamente violentados e mortos pelos cobiçadores das terras onde viviam (Arnaud, 1964; Ferraz, 1998; Laraia, Da Matta, 1978).

A ida dos grupos Timbira para a TI Máe Maria traçou um corte radical na história desses sujeitos, que passaram a lidar instantaneamente com a negociação da castanha produzida em suas terras, num período em que essa atividade tinha inserção no mercado internacional e trazia grande rentabilidade ao município de Marabá. Além desse fator, os Gavião continuaram lidando com os interesses do capital sobre o território demarcado, o que levou a negociaçóes do uso de suas terras com empresas para possibilitar a passagem de grandes empreendimentos.

Nesse embate constante de proteção da TI Mãe Maria, os Gaviáo precisam lidar com diferentes forças, desde caçadores, pescadores, coletores externos até 
grandes empresas e instituiçóes governamentais. A passagem de estradas como a BR-222, a implantação de linhóes de energia da Eletronorte e a Estrada de Ferro Carajás, para escoamento de minério da Vale, além da ameaça de eliminação de seus rios para futuras construçóes de hidrelétricas no rio Tocantins, são alguns dos maiores enfrentamentos dos Gavião nesses anos de conflitos e negociaçóes.

Diante de todo esse contexto, é importante então balizar a relação entre a entrada dos alunos Gavião (assim como outros povos indígenas do Brasil) na universidade com as lutas pelo território de suas comunidades, ${ }^{4}$ a produção dos Trabalhos de Conclusão de Curso (TCCs) desses discentes, ${ }^{5}$ etc. A intensificaçáo das disputas por território coloca os indígenas em constante posição de defesa e de luta por direitos em decorrência desse contato sistemático com o homem branco, provocando diversas demandas sociais como a formação acadêmica, de forma a garantir maior autonomia diante das novas dinâmicas que passam a ter os povos indígenas em função desse contato.

Com todas essas mudanças impostas aos Gavião ao longo do tempo, de sua sobrevivência girar em torno da defesa e negociaçáo de seus territórios pela cobiça de empresas e da sociedade nacional de forma geral, a necessidade de se apropriar dos conhecimentos do kupen para lidar com ele tornou-se imperativo. Essa necessidade explica a crescente exigência dos indígenas pela educação nãoindígena e, a partir do fim século XX, especificamente pela educação de nível superior.

\title{
Compreensões da roda de conversa na relação com a Dialogia, com a História Oral e Análise do Discurso
}

\author{
A importância do silêncio no espaço da comunicação é funda- \\ mental. Ele me permite, por um lado, escutar a fala comunicante \\ de alguém, como sujeito e não como objeto, entrar no movimento \\ interno do seu pensamento, transformando-me em linguagem;
}

4 Sobre essa perspectiva, ver texto de Antonio Hilario Aguilera Urquiza "Indígenas na Educação Superior e Possibilidades de Diálogo Intercultural: a experiência do Programa Rede de Saberes - MS/Brasil" publicado na Revista del Instituto de Investigaciones en Educación em 2016. Disponível em: < https:// hum.unne.edu.ar/revistas/educa/archivos/cont8/art4_aguileraurquiza.pdf $>$. Acesso em: 24 jun. 2020 .

5 A esse respeito, em artigo a ser publicado em breve na revista Agenda Social, apontamos as abordagens tratadas na produção dos TCCs dos discentes indígenas na Unifesspa formados até o ano de 2018. Ver Dossiê 2020/1: Mídia e Discurso na Amazônia: Interculturalidade e Resistência (http://www. revistaagendasocial.com.br/index.php/agendasocial/index). 
por outro lado, torna possivel a quem fala, realmente comprometido com o comunicar e não o fazer comunicado, ouvir a dúvida, a indagação, a criação daquele que escuta.

Ninguém educa ninguém, nem ninguém se educa a si mesmo, os homens se educam em comum mediados pelo mundo. (Paulo Freire)

A roda de conversa é recente como método de pesquisa, mas já usada há bastante tempo em sala de aula por professores inspirados na concepção freiriana de ensino libertador com práticas de mútua aprendizagem entre professor e aluno. Das salas de aula, especialmente do ensino infantil e fundamental, a roda de conversa tem ganhado espaço também em momentos acadêmicos de reflexão e, desse lugar, expandiu-se como prática de geração de dados em pesquisas científicas.

Provavelmente, quem inventou a roda de conversa foi Sócrates (469-399 a.C.), que de início promovia habitualmente uma troca de ideias com seus interlocutores, estimulando a reflexão e caracterização de algumas qualidades e virtudes [...] Uma aprendizagem significativa, vista como a compreensão de significados, que se relaciona às experiências anteriores e vivências pessoais dos aprendizes, permitindo a formulação de problemas desafiantes que incentivam o aprender mais, o estabelecimento de diferentes tipos de relaçóes entre fatos, objetos, acontecimentos, noçóes e conceitos, desencadeando modificaçóes de comportamentos e contribuindo para a utilização do que é aprendido em diferentes situaçóes. (Melo et al., 2016, p. 302).

Tal possibilidade de aprendizagem com o outro e de formação política pela interação é também um princípio fundamental nas discussóes produzidas pelo Círculo de Bakhtin. Nessa perspectiva teórica, o processo de dialogismo estabelecido pelas interaçóes possibilita a formação política do sujeito por meio da relaçáo com o outro.

A verdadeira substância da língua não é constituída por um sistema abstrato de formas linguísticas nem pela enunciação monológica isolada, nem pelo ato psicofisiológico de sua produção, mas pelo fenômeno social da interação verbal, realizada através da enunciação ou das enunciaçóes. (Bakhtin, 1997, p. 123).

Assim, entendemos a roda de conversa com potencialidade para proporcionar 
a (re) construção dos conhecimentos a partir da interação com os interlocutores, admitindo com o autor que

Toda palavra comporta duas faces. Ela é determinada tanto pelo fato de que procede de alguém, como pelo fato de que se dirige para alguém. Ela constitui justamente o produto da interação do locutor e do ouvinte. Toda palavra serve de expressão a um em relação ao outro. Através da palavra, defino-me em relação ao outro, isto é, em última análise, em relação à coletividade. A palavra é uma espécie de ponte lançada entre mim e os outros. Se ela se apoia sobre mim numa extremidade, na outra apoia-se sobre o meu interlocutor. A palavra é o território comum do locutor e do interlocutor. (Bakhtin, 1997, p. 117, grifos nossos).

A escolha da roda de conversa como método para manifestação das falas dos alunos cumpre, entáo, para nós duplo papel: o de nos possibilitar ter acesso aos enunciados que precisávamos para a pesquisa e também proporcionar aos alunos um momento de discussão para construção política de sua forma-sujeito. Assim, interpretamos os efeitos da tomada de consciência desses alunos sobre a temática das rodas, que eram o acesso e a permanência deles na universidade.

Percebendo essas lacunas e a tomada de consciência dos alunos em torno do racismo institucional no debate e reflexáo coletivos, a roda se revela como potente ferramenta de politização, como mostraremos no quarto tópico deste artigo. Portanto, por essas nuances é que se difere o homem isolado do homem membro "de uma coletividade unida por vínculos materiais objetivos [tendo menos condiçóes para que neste haja lugar] ...pra uma mentalidade resignada e submissa" (Bakhtin, 1997, p. 120).

Outra percepção importante somada à compreensão das rodas de conversa é a de tomar os enunciados dos alunos como materialidade histórica (nos preceitos de Portelli): a versão dos fatos não contada nas fontes legitimadas de registros históricos. Para fazer frente a essa lacuna comum aos grupos de tradição oral, ou que náo dominam a escrita padrão que os possibilite escrever e publicar livros sobre a história a partir de seu ponto de vista, é que tem tomado expressão como fonte de pesquisas acadêmicas a História Oral: "as fontes orais dão-nos informaçóes sobre o povo iletrado ou grupos sociais cuja história escrita é ou falha ou distorcida" (Portelli, 1997, p. 27).

O autor defende que a História Oral é importante tanto pelos eventos quanto pelos significados, pois revela faces desconhecidas da história ao visibilizar experiências não hegemônicas silenciadas (Portelli, 1997, p. 31). No que tange aos significados, as fontes "orais podem náo adicionar muito ao que sabemos, o curso material de uma greve para os trabalhadores envolvidos; mas contam-nos 
bastante sobre seus custos psicológicos" (Portelli, 1997, p. 31). Dessa forma, o autor vai destacar justamente no seu distanciamento da verificação factual dos documentos escritos a credibilidade da História Oral, pois a

[...] importância do testemunho oral pode se situar não em sua aderência ao fato, mas de preferência em seu afastamento dele, como imaginaçáo, simbolismo e desejo de emergir. Por isso, não há 'falas' fontes orais [...] a diversidade da história oral consiste no fato de que afirmativas 'erradas' são ainda psicologicamente 'corretas', e que esta verdade pode ser igualmente tão importante quantos registros factuais confiáveis. (Portelli, 1997, p. 32).

Nesse sentido é que entendemos os enunciados dos alunos, colocando-os num patamar de importância histórica, como narrativas dos "homens infames da história" (dialogando com Foucault), ${ }^{6}$ os que não encontram espaço nas narrativas oficiais.

Por fim, acreditamos que nas rodas de conversas os alunos puderam refletir sobre o tema pesquisado, desnaturalizando conceitos e possibilitando novas atitudes no meio sobre o qual se está refletindo, no nosso caso, o acadêmico. Enquanto características metodológicas das rodas, sobressaem-se sua potencialidade agregadora e a garantia de participação democrática dos integrantes por, pelo menos, dois motivos básicos: a não hierarquização dos participantes, já que a fala é franqueada a todos e a necessidade imperativa de que todos participem, de forma que isso fique claro e evidente. $\mathrm{O}$ formato em círculo também induz à compreensão da importância da passagem de fala ao outro, ainda que não seja na ordem na disposição dos corpos, mas também pelo simples desejo de falar porque, por exemplo, se sentiu motivado por algum ponto mencionado anteriormente.

Ou seja, o momento da roda se evidencia como um espaço inoportuno à segregação ou assimetrias entre os participantes, especialmente porque esse caráter de funcionamento é explicitado aos envolvidos, tentando garantir igualdade na oportunidade de fala na compreensão de que nesse percurso da escuta do outro possibilita-se a aprendizagem mútua.

Depois de concluídas as rodas nas três aldeias, trabalhamos na transcrição das mesmas e depois de muitas leituras fomos percebendo as aproximaçóes e dispersóes dos enunciados, o que possibilitou a organiza-los por temas, na perspectiva enunciativa de Foucault (2014). Ou seja, enfeixamos os enunciados

"A vida dos homens infames" é um texto de Foucault resultante de pesquisa em arquivos (cartas régias, ordens de prisão) da polícia e internatos, onde define "homens infames" os que não tiveram suas histórias marcadas na história: "pobres espíritos perdidos pelos caminhos desconhecidos, estes são infames com a máxima exatidão" (Foucault, 2006, p. 210). 
compreendendo-os nos entrelaçamentos que ele próprio materializa com a história e com os discursos, com os "conteúdos concretos" dos meandros sociais, políticos e culturais que formam e tencionam os ordenamentos, emergindo daí os sentidos das narrativas que produzem por meio da identificação das regras que os controlam e do campo onde se realizam.

\section{O encaminhamento da adoção da roda de conversa como ferramenta metodológica para acesso às narrativas}

Enquanto estiveram juntos, participaram do mesmo interesse, tinham um foco comum de atenção e suspenderam, ou adiaram, outras atividades e compromissos. Compartilharam de algum tempo, de uma definição comum de realidade, operaram na mesma provincia de significado, nos termos de Alfred Schutz. Interagiram através de uma rede de significados, conforme a definição de Geertz. Atuaram dentro de um sistema compartilhado de crenças e valores. Mesmo admitindo uma certa variação individual, o comportamento e a atitude dos participantes apresentavam notável homogeneidade.

(Otávio Velho)

Reservamos este tópico para melhor esclarecer e refletir sobre o encaminhamento e resultados da metodologia operacionalizada nas aldeias: a roda de conversa. Julgamos por bem esclarecer o porquê das escolhas operacionais, entendendo que o como desenvolver a pesquisa também deve dar passos coerentes com os sentidos epistemológicos e políticos defendidos no trabalho como um todo.

Cientes da contraproducência de generalidades ao propor refletir sobre "indígenas" na "universidade", tomamos como referência os processos ocorridos em uma experiência específica. Analisamos as peculiaridades da Unifesspa, entre tantas universidades, e as dos estudantes Gavião, entre tantas etnias presentes na instituição. Considerando as limitaçóes temporais e de recursos humanos para o desenvolvimento da pesquisa, traçar as escolhas metodológicas é uma necessidade operacional para a viabilidade de execuçáo. Assim, na impossibilidade de 
percorrer as 16 aldeias do povo Gavião, estabelecemos como recorte três aldeias e justificamos essa escolha por serem elas as três primeiras aldeias existentes na TI Mãe Maria (Parkatêjê, Akrãtikatêjêe e Kyikatêjê), e com maior número de alunos na Unifesspa. A Unifesspa foi a universidade escolhida por ser a universidade federal com maior presença na região e com maior entrada de estudantes indígenas. Esse recorte que especificou um grupo e uma universidade se desenhou como uma alternativa viável considerando os cuidados necessários quando se trata de uma pesquisa com esse perfil, onde deve estar clara a compreensão de que nenhuma universidade é igual à outra e também as etnias indígenas não devem ser tratadas numa perspectiva homogênea.

Considerando o caso específico foi o que nos permitiu fazer consideraçóes mais profícuas acerca da relaçáo entre universidades e indígenas. Por outro lado, percebemos também que as especificidades do caso estudado podem ser generalizadas, resguardando as devidas ponderaçóes. Assim, pudemos afirmar que as experiências vivenciadas pelos alunos Gaviôes são comuns também aos alunos das demais etnias presentes na Unifesspa e mesmo em outras universidades do Brasil, a partir do que levantamos na revisão bibliográfica. Naturalmente, são experiências marcadas pelas idiossincrasias desses outros indígenas, dessas outras universidades e suas respectivas histórias com as sociedades que os cercam e também entre si.

Um outro entendimento da pesquisa é o ato político de partir da experiência dos alunos para refletir sobre as dificuldades que levam à evasão indígena na graduação, considerando que ninguém melhor que o próprio aluno para falar do seu lugar, único, e impossível de ser sentido e transmitido por outro sujeito. Por isso a importância de ouvir os discentes tomou tamanha relevância. Com isso, entrevistas com as lideranças indígenas, com servidores e professores da Unifesspa foram de suma importância para compreensão de diversos ângulos do problema, mas os enunciados oriundos das rodas de conversa é que ocupam centralidade no nosso fazer científico, para buscar as respostas aos problemas expressos nos objetivos da pesquisa.

Definido isso, chegamos então ao impasse de definir o método para conhecer essas narrativas. De antemão, a entrevista já era um caminho pelo qual não consideramos seguir, admitindo que a relação assimétrica assumida na percepção "pesquisador" x "entrevistado" poderia interferir diretamente na expressão da subjetividade dos alunos, especialmente considerando que normalmente os jovens indígenas não se sentem muito à vontade para falar publicamente, especialmente pelo fato de que na tradição desses povos a fala pública é franqueada majoritariamente entre os mais velhos e as lideranças. Outra questão contra a entrevista é a compreensão política de como o entrevistado é 
tomado nesse contexto de pesquisa, numa perspectiva exploratória.

Diante disso, inicialmente ofertei oficinas de leitura e produção textual na universidade para esses alunos, a fim de contribuir com as carências desse grupo no âmbito da linguagem acadêmica e também para me aproximar deles. Essa metodologia teve pouca adesão. Nas diversas tentativas, poucos alunos compareceram, alegando outros afazeres na aldeia ou com os trabalhos do curso de graduação. Foi aí então que se acenou a necessidade de ir à aldeia para interagir com os alunos, considerando que lá se sentem mais à vontade e também teriam mais facilidade para reservar um momento para atender aos interesses da pesquisa.

Outro ponto positivo que me fez entender ser mais vantajoso promover o conhecimento das narrativas na aldeia foi o fato de ampliar a possibilidade de agregar um número maior de alunos, visto que na universidade eles estudam em horários diferentes e sempre, de qualquer forma, um número significativo de possíveis interlocutores ficariam de fora das oficinas, caso tivesse dado seguimento a elas. A preocupação de náo coincidir com os horários de aula dos alunos, levounos também à decisão de tentar reunir os alunos aos domingos, atendendo a uma sugestão dos caciques que alertaram ser esse o dia da semana em que todos eles estão sem aula e presentes na aldeia.

Com esse encaminhamento de amadurecer melhor a forma de interagir com os alunos, fui me dando conta de que teria de ser uma atividade em conjunto (pelo que envolve de expressividade pública, como pontuamos há alguns parágrafos), com potencialidade para minimizar os efeitos da inevitável formalidade que compromete a manifestação das subjetividades dos alunos de forma mais espontânea. Nesse momento foi que pensei nas rodas de conversa, uma vez que ela já vem sendo utilizada como abordagem legítima em pesquisas acadêmicas, garantindo-nos o rigor científico exigido de uma pesquisa com objetividade, considerando ainda a triangulação entre as narrativas das rodas e as demais fontes de dados utilizadas na pesquisa.

A opção pela roda de conversa também se reforçou como uma possibilidade pelo fato de que a universidade onde estudam já ter proporcionado atividades nesse formato a esses discentes, de forma que náo seria algo estranho aos nossos interlocutores. Além disso, consideramos também que a roda de conversa tem proximidade com as práticas de oralidade nas aldeias nos momentos de aprendizagem com os mais velhos.

Para o desenvolvimento desses encontros, realizamos, de 2017 a 2018, nove visitas nas aldeias de alunos Gavião Parkatêjê, Akrãtikatêjê e Kyikatêjê, sempre por meio de contato iniciado com as lideranças para explicar os objetivos da pesquisa, os quais foram unanimemente compreendidos e avaliados como de relevância significativa pelas mesmas, a tal ponto de autorizarem a realização da 
pesquisa na aldeia e o contato com os alunos, além de o/a(s) cacique(s) também se responsabilizarem pela mobilização dos alunos para os encontros.

Para a realização dos encontros nas aldeias, em algumas delas, foi necessário mais de uma visita, pois a primeira foi justamente para prestar esses esclarecimentos e ter o consentimento das lideranças para realização da pesquisa com os graduandos e, em outros casos, não foi possível iniciar as rodas de conversa, mesmo com agendamento prévio, por motivos de luto ou outros imprevistos políticos pelos quais as lideranças tiveram que se ausentar. Cada uma dessas visitas durou um turno inteiro, geralmente uma manhã.

Foram declarados anteriormente os motivos para a escolha de estudantes

\begin{tabular}{|c|c|c|c|c|c|c|c|c|c|c|c|c|c|c|c|}
\hline \multirow{3}{*}{ Etnia } & \multicolumn{14}{|c|}{ Anos de Ingresso/Sexo } & \multirow{3}{*}{ Total } \\
\hline & \multicolumn{2}{|c|}{2010} & \multicolumn{2}{|c|}{2011} & \multicolumn{2}{|c|}{2012} & \multicolumn{2}{|c|}{2013} & \multicolumn{2}{|c|}{2014} & \multicolumn{2}{|c|}{2015} & \multicolumn{2}{|c|}{2016} & \\
\hline & $\mathrm{F}$ & $\mathrm{M}$ & $\mathrm{F}$ & $\bar{M}$ & $\mathrm{~F}$ & $\mathrm{M}$ & $\mathrm{F}$ & $\mathrm{M}$ & $\mathrm{F}$ & $\mathrm{M}$ & $\mathrm{F}$ & $\mathrm{M}$ & $\mathrm{F}$ & $\mathrm{M}$ & \\
\hline Aikewara & - & - & - & - & - & 01 & - & - & - & 01 & - & - & - & - & 02 \\
\hline Aticum & - & 02 & - & - & - & - & - & - & - & - & - & 01 & 01 & - & 04 \\
\hline Xiquitano & - & - & - & - & - & - & - & 01 & - & - & - & - & - & - & 01 \\
\hline Gavião & 01 & 03 & 03 & 05 & 04 & 03 & - & 01 & 01 & - & 09 & 05 & 08 & 09 & 52 \\
\hline Guajajara & - & - & - & - & - & & 02 & - & - & - & 01 & - & 02 & 02 & 07 \\
\hline Guarany & - & - & - & - & - & - & - & - & - & 01 & - & 03 & - & - & 04 \\
\hline Kaiapó & - & - & - & - & - & - & - & - & - & 01 & - & - & - & 01 & 02 \\
\hline Karajá & - & 01 & 01 & 01 & - & - & 01 & - & - & - & 02 & - & 01 & 05 & 12 \\
\hline Tembé & - & 01 & - & - & - & - & - & 01 & - & - & - & - & - & - & 02 \\
\hline Tupiniquim & - & - & - & - & - & - & - & - & - & - & 01 & - & - & - & 01 \\
\hline Xerente & 03 & 02 & - & - & - & - & 01 & - & - & - & - & 01 & - & - & 07 \\
\hline Xikrin & - & - & - & - & - & - & - & - & - & - & - & - & - & 02 & 02 \\
\hline Total & 04 & 09 & 04 & 06 & 04 & 04 & 04 & 03 & 01 & 03 & 13 & 10 & 12 & 19 & 96 \\
\hline
\end{tabular}

Tabela 1 - Número de alunos ingressos por etnia, ano e sexo Fonte: Pesquisa Diagnóstico (UNIFESSPA, 2016)

Gaviáo e para respaldar a informação de que são em maior número na Unifesspa, no recorte temporal dos dados utilizados na pesquisa, entre 2010 e 2016, dos 96 indígenas ingressantes na Unifesspa, 52 são da etnia Gavião, conforme tabela abaixo.

Como podemos notar nesses dados acima, o número de alunos Gavião é bem maior que os das demais etnias, o que justifica nosso recorte, possibilitando condiçóes favoráveis de ouvirmos um número considerável de discentes de uma mesma etnia. Ao todo, participaram da pesquisa 23 graduandos.

Foram convidados para participar das rodas aluno(a)s em curso ou desistentes, motivadas pelos seguintes questionamentos: Quais as principais dificuldades para permanecer na universidade? Quais as implicaçóes do fator étnico na vivência 
acadêmica? Qual o propósito de cursar a graduação?

Nisso, ratifica-se a importância da figura do moderador, que deve ser transparente quanto aos objetivos da roda de conversa e como as falas serão usadas posteriormente na pesquisa, inclusive, acordando com a identificação ou não dos participantes. No caso da nossa pesquisa, antes de franquear a fala aos interlocutores, discutimos essas questóes.

Os enunciados dos alunos foram tomados na pesquisa tanto no corpus de análise quanto como fonte histórica, na perspectiva da História Oral. Porém, o corpus de análise discursiva da pesquisa não se limita aos enunciados dos alunos, mas também recorre a uma rede de enunciados alocados em práticas discursivas, como: entrevista com as lideranças indígenas; entrevistas realizadas com professores da Unifesspa, observaçóes em eventos acadêmicos na Unifesspa sobre temáticas indígenas; documentos e dados institucionais da Unifesspa; Projetos Pedagógicos de Cursos (PPCs); dados do Ministério da Educação (MEC); registros de acontecimentos na universidade; além de dados históricos. Ao relacioná-los, percebemos entáo os enunciados em rede com os vários outros acontecimentos sócio-históricos, políticos, culturais e econômicos, possibilitando estabelecer os sentidos presentes nas narrativas.

Para estabelecermos o recorte temporal necessário à coleta de dados (número de matrículas e alunos desistentes, documentos, etc.) e consideraçóes a serem feitas, consideramos o período entre 2010 e 2016. Isso porque 2010 foi quando teve início as açóes afirmativas para indígenas na Unifesspa e 2016 foi quando iniciamos a pesquisa.

\section{Considerações quanto as idiossincrasias e benefícios da adoção da roda de conversa como metodologia na pesquisa}

Para exemplificar o efeito politizador que acreditamos ter a roda de conversa, como efeito das trocas dialógicas com o outro, conforme a perspectiva bakhtiniana, os enunciados a seguir evidenciam a tanto construçáo da narrativa coletiva quanto suas vivências na universidade. O termo "construção de narrativa" é importante pelo fato de que inicialmente a maioria dos alunos náo tinham certeza se suas subjetividades envolvendo o espaço institucional seriam de interesse da roda e acabavam inicialmente elencando dificuldades evidentemente mais concretas para a permanência na universidade, como limitaçóes financeiras, transporte, etc.

Porém, quando algum participante toca na questáo do racismo institucional, 
todos os participantes da roda passam a querer falar sobre essas questóes prioritariamente e percebem, então, que suas subjetividades são comuns e de interesse coletivo, logo, uma pauta política.

Abaixo trouxemos apenas alguns poucos relatos dos discentes, com trechos que grifamos para melhor compreensão do que viemos tratando até aqui. Os nomes dos (as) alunos (as) não foram identificados, informando apenas o curso onde estavam vinculados.

[...] mas eu vejo o esforço da universidade de buscar, de mostrar para os alunos que existe saber da história que Marabá tem uma grande população indígena. É importante que vai quebrar essa barreira não vai ser agora mais fazendo essa divulgação e o trabalho da senhora é de suma importância porque vai facilitar a vida de muitos indígenas que vão entrar na universidade porque sabendo da história já tira muito desse preconceito que é passado até pelo ensino para ele de como é o indígena tem que ser petrificado que é uma relíquia [...] então tem que divulgar tem que mostrar esse outro lado mesmo nosso. Às vezes a gente vai na rua e as pessoas fica olhando para gente, assim... Já tem mais de cinquenta e poucos anos que sempre teve indígena aqui na região o povo ainda tem essa visão de estranhamento? Mas por que que não sabe da história de Marabá que sempre existiu população indígena ao redor são mais de 15 aldeia indígena. Mas no meu e porquê ponto de vista o preconceito sempre vai existir porque é uma batalha imensa. (Aluno do Curso de Geografia, 2016).

Eu acho que esse os professores da Unifesspa deveriam conhecer mais nós povos indígenas, deveriam estudar mais um pouco a história indígena porque os que estão ali não estão preparados para dar aula pra nós realmente. (Aluna do Curso de Pedagogia, 2017).

Sempre ouvi bastante essa dificuldade e sempre a conversa é a mesma dessa exclusão mesmo dos colegas e alguns professores tem essa visão de [...] processo assim mas não sabe do histórico do aluno para chegar naquele momento lá. (Aluno do Curso de Economia, 2016).

Primeiramente na fase que foi para entrar o PSE, já falaram 'você aqui?'. Tipo: 'uma indígena aqui' [...] uma vez um professor falou assim 'seu nome é diferente'. Aí eu disse 'é porque eu sou indígena'. Aí ele ficou surpreso 'uma indígena aqui na sala?' e eu falei 'não, somos duas'. E a outra colega falou que tinha quilombolas também. 'Quilombolas?' é. E aí se apresentou mais duas que não passaram com a gente. E aí eu levei isso para reunião falei que 
os professores nem sabia que tinha indígena na sala e aí ela sorriu e falou: 'ah! mas aí é vocês que tem que falar'. A universidade que tinha que dizer: 'olha, vai entrar indígena, vai entrar indígena e vocês se prepare’. Não. É vocês que vão ter que se virar e apresentar para os professores. Até porque tem indígena que não tem aquela característica forte como eu que entrei lá. (Aluna do Curso de Direito, 2016).

Quando eu fui fazer a inscrição, nem as pessoas do curso sabiam que o curso tinha cota, aí eu mostrei que eu tinha passado. (Aluna do Curso de Educação do Campo, 2017).

Os enunciados dos alunos evidenciam o apagamento da entrada indígena na instituição, uma prática que reforça os preconceitos e racismo em alunos e colegas não-indígenas, especialmente nos que menos conhecem a diversidade de povos que compóem a história e vida regional. Apesar de que o "desconhecimento" ou a "falta de informação" não serem os únicos fatores para explicar o racismo, visto que em muitos casos saber sobre os vários aspectos de opressão em torno de uma etnia não é suficiente para acabar com eles, é inegável que as práticas institucionais devem ser pautadas na circulação de informação sobre os indígenas na região no intuito de legitimá-los no espaço acadêmico enquanto constituintes da história local, como forma de fundamentar as políticas específicas para esse povo diante de professores, servidores e alunos resistentes a açóes de acesso e permanência enquanto açóes afirmativas.

Assim que é fundamental a atuação das instituições no exercício de direitos já garantidos pelo Estado aos grupos indígenas como forma de instrumentalizá-los na luta por implementação de mudanças institucionais. Júlio José Araújo Junior se refere a essa garantia de direitos (mencionando a teoria de Will Kymlicka) como "proteçóes externas":

As proteçôes externas são fundamentais para garantir os modos de organização dos povos indígenas, enquanto grupo e individualmente. Nesse sentido, a proteção territorial ganha especial relevância, assim como todos os aspectos atinentes às suas peculiaridades socioculturais (trabalho, saúde, educação). (Araújo Junior, 2018, p. 191).

No quesito "educaçáo", mencionado como um aspecto primordial para o fortalecimento da luta indígena pela sua existência (condicionada à proteção de suas terras e suas culturas), já existem um leque de formulaçóes legais que possibilitam essa instrumentalização (enquanto "proteção externa") dos povos indígenas na exigência de melhorias. É por meio desse conjunto de leis e diretrizes 
que os movimentos indígenas podem fundamentar o enfretamento ao racismo e gerar novas práticas positivas nas Instituiçóes de Ensino Superior (IESs), o que inevitavelmente reverbera na sociedade como um todo; a adoção da temática Educação para as Relaçóes Étnico-Raciais (ERER) nos diversos âmbitos que constituem a universidade, em especial o educacional, o que não exclui os de pesquisa e extensão. Para tanto, há um conjunto de leis, resoluçóes e pareceres que amparam a aplicabilidade da ERER nas IESs.

$\mathrm{O}$ documento que reúne todas essas orientaçóes e amparos legais para a adoção da temática educação das relaçóes étnico-raciais é o "Plano Nacional de Implementação das Diretrizes Curriculares Nacionais para Educação das Relaçóes Etnicorraciais e para o Ensino de História e Cultura Afrobrasileira e Africana” (Brasil, 2009).

Com os relatos apresentados, é evidenciado o quanto a presença indígena tem tensionado a universidade e também, por outro lado, o quanto a universidade não pode se furtar de dar respostas dentro desse processo de interpelação. ${ }^{7}$

Diante do que foi apresentado neste tópico sobre o uso das rodas de conversa como estratégia de interação com os alunos nas aldeias, destacamos a participação significativa dos estudantes que estavam presentes, o que foi bastante satisfatório para a pesquisa, pois demonstra a importância dada pelas comunidades ao trabalho.

Além da presença física, as rodas foram momentos de interação e de trocas importantes, como demonstramos nos enunciados acima, chamando-nos a atenção para compreendermos o aluno indígena Gavião como aquele sujeito que tem a coragem de ir contra os ordenamentos postos e enunciar suas subjetividades. Abordamos o processo de construção das narrativas em torno das vivências no contexto educacional no qual estavam envolvidos os alunos, enxergandoos envolvidos na construçáo da forma-sujeito, do que é interpelado pelo ato de coragem para falar em "uma coletividade unida por vínculos materiais objetivos", nos termos de Bakhtin (1997).

Para se colocar nesse lugar enunciativo, de denúncia voluntária e passível de identificação, é necessário coragem. E o fazem por perceberem nessa fala um ato político, a possibilidade de lutar por mudança, sendo a fala, o enunciado, o próprio ato de luta, com a consciência dos riscos de dizer. E falam pela necessidade de se ligarem a esse enunciado da construção coletiva enquanto sujeitos, proporcionado nas rodas de conversa.

A análise dos enunciados gerados nas rodas de conversa evidencia os sentidos

Sobre essa questão, voltamos a citar o artigo (ver nota 5) a ser publicado na revista Agenda Social, onde analisamos o impacto da graduação para as comunidades indígenas e, por outro lado, quais as fissuras possibilitadas na Unifesspa em função da presença indígena, na perspectiva da interculturalidade. 
de uma narrativa que se converge em luta (não apenas instrumento de luta), visto que é no e pelo enunciado dito que há disputa, na materialização da linguagem tanto em regularidades (a repetição) quanto em dispersões presentes nas narrativas evidenciadas nas falas dos alunos.

Dessa forma, as questōes em torno da presença indígena na Unifesspa foram visibilizadas nesses (en)cadeamentos enunciativos, evidenciando essas regularidades e as divergências, o que possibilita identificar, por exemplo, a constituição homogênea e colonial das universidades brasileiras, os traços de subjetividades comuns aos alunos e uma série de fatores que compóem as demandas coletivas dos povos indígenas de forma geral diante das políticas públicas/açóes afirmativas.

\section{Considerações finais}

Ao apresentar as peculiaridades metodológicas de nosso estudo, os engendramentos e a compreensão que tivemos sobre o como do fazer científico, esperamos ressaltar a importância do estabelecimento de uma metodologia que dialogue com a identidade da pesquisa à qual atende. Com isso, pontuamos neste artigo as escolhas que foram feitas para construção de um método que contemplasse a teoria adotada, o objetivo do trabalho e, especialmente, os sujeitos envolvidos no estudo.

Nesse sentido, a pesquisa só encontrou viabilidade quando conseguimos estabelecer um método que levasse em consideração as condiçôes dos indígenas e toda a concepção epistemológica assumida no estudo.

Ressaltamos que as rodas de conversa não compóem o único recurso da metodologia da pesquisa (como apontamos no tópico anterior), pois buscamos também diversas outras fontes de dados a fim de triangular com os enunciados dos alunos. Mas foram as rodas que nos permitiram conhecer as narrativas dos graduandos indígenas a respeito de suas experiências com a universidade, depois de tentarmos, sem êxito, outros métodos.

Na realizaçáo das rodas de conversa com esses sujeitos e com os tensionamentos que buscamos nessa experiência em específico, podemos listar pelo menos três identificaçôes de coerência teórico-metodológica: a identificação da roda de conversa com o dialogismo, com a Análise do Discurso e com a História Oral.

A linguagem é um campo que permeia inevitavelmente a roda de conversa e as tentativas de compreensão da mesma inevitavelmente retomam esse campo do conhecimento em específico. Logo, como pesquisadora da área de linguística, chamou-me a atenção na metodologia sua potencialidade de politização na 
perspectiva do dialogismo, que preconiza a formação política pela interação.

Ainda no campo da linguagem, a experiência com a roda de conversa responde à uma lacuna metodológica em pesquisas da Análise do Discurso que exigem trabalho de campo. Nesse caso, as narrativas dos alunos produzidas nas rodas, sendo tomados na perspectiva de enunciado, possibilitam a análise das mesmas no viés discursivo, quando por análise discursiva se conceber a compreensão de enunciados no entrelaçamento com os "conteúdos concretos" dos meandros sociais, políticos e culturais que constituem ordenamentos na sociedade.

A terceira identificação teórico-metodológica das rodas é com a História Oral, servindo com eficácia para pesquisas que visem tomar os enunciados dos interlocutores como materialidade histórica a partir de uma percepçáo coletiva de memória e de subjetividades não hegemônicas e silenciadas sobre um acontecimento histórico ou um aspecto do funcionamento da sociedade.

Quanto ao funcionamento das rodas, identificamos uma capacidade altamente agregadora das mesmas por seus participantes se sentirem envolvidos, tocados e motivados a falar à medida que ouvem os relatos de outros, impelidos à necessidade de contribuição a partir do conhecimento que possuem sobre o tema. Com isso, revela-se outra faceta da roda de conversa, que é a valorização do conhecimento pessoal dos sujeitos, considerando que a experiência de cada um será ouvida e somada ao conjunto de informaçôes que irá compor a narrativa resultante da experiência na qual se está envolvido.

O caráter democrático da roda também é um fator a ser destacado, pois confirmamos em nossas experiências que o formato em círculo envolve os participantes em uma lógica de rodízio de fala, evidenciando a possibilidade igualitária de todos falarem e que toda fala é importante.

Além disso, evidenciou-se que o falar é a ação que concretiza a inserção dos sujeitos na roda, o falar na roda é o ato político que o insere no pertencimento a esse todo no qual está posto de forma corpórea. O falar é como se fosse a manifestação da aceitação de pertencimento a esse todo, a confirmação de sua presença, de fato, e o assentimento para identificação com esse grupo e/ou com a temática tratada.

Apesar de diversos outros aspectos que assentam sobre as rodas de conversa como ferramenta metodológica para pesquisa, na área das ciências humanas especialmente, essas foram as percepçóes diretamente relacionadas à pesquisa que desenvolvemos, as quais pontuamos certos de que podem inspirar e auxiliar outras pesquisas no uso da roda de conversa como caminho metodológico pertinente. Nisso, salientamos que o caminho percorrido não será necessariamente o mesmo, pois nossas escolhas, como descrevemos, resultaram de uma série de condicionamentos sócio-históricos, o que certamente é peculiar em cada pesquisa social. 


\section{Referências}

ARAÚJO JUNIOR, Júlio José. A Constituição de 1988 e os direitos indígenas: uma prática assimilacionista? In: CUNHA, Manuela Carneiro da; BARBOSA, Samuel Rodrigues (Org.). Direitos dos povos indígenas em disputa. São Paulo: Editora Unesp, 2018.

ARNAUD, Expedito Coelho. Notícias sobre os índios Gavióes do Oeste - Rio Tocantins, Pará. Boletim do Museu Paraense Emílio Goeldi, Nova Série Antropologia, Belém, n. 20, p. 1-35, mai. 1964.

BAKHTIN, Mikhail. Marxismo e filosofia da linguagem. 16a ed. São Paulo: Hucitec, 2014.

BRASIL. Ministério da Educação. Plano Nacional de Implementação das Diretrizes Curriculares Nacionais para Educaçáo das Relaçóes Etnicorraciais e para o Ensino de História e Cultura Afrobrasileira e Africana. Brasília: MEC, 2009. Disponível em: <http:// portal.mec.gov.br/index.php?option=com_docman\&view=download\&alias=10098diretrizes-curriculares\&category_slug=fevereiro-2012-pdf\&Itemid=30192>. Acesso em: 19 jun. 2018.

FERNANDES, Ana Paula de Souza; GUIDO, Claudiana Gomes; RODRIGUES, Lidiane Neves. Aplicabilidade da ERER na Unifesspa: um estudo a partir dos NDEs e discentes dos cursos de Letras e História. Monografia (Especializaçáo em Saberes Africanos e Afrobrasileiros na Amazônia) - UFPA, Belém, PA, 2016.

FERRAZ, Iara. De 'Gaviōes' a 'Comunidade Parkatêjể: uma reflexão sobre processos de reorganização social. Tese (Doutorado em Antropologia Social) - UFRJ, Rio de Janeiro, RJ, 1998.

FOUCAULT, Michel. A arqueologia do saber. Rio de janeiro: Forense Universitária, 2014.

A vida dos homens infames. In: MOTTA, Manoel Barros da (Org.) Estratégia, poder-saber. 2. ed. Tradução Vera Lúcia Avelar Ribeiro. Rio de Janeiro: Forense Universitária, 2006. (Ditos e escritos; IV) p. 203-222.

Outros espaços. In: Estética: literatura e pintura, música e cinema. Coleção Ditos \& Escritos III. Rio de Janeiro: Forense Universitária, 2005.

GOMES, Mércio Pereira. Os indios e o Brasil: passado, presente e futuro. São Paulo: Contexto, 2017.

LARAIA, Roque de Barros; DA MATTA, Roberto. Índios e castanheiros: a empresa extrativa e os índios no médio Tocantins. Rio de Janeiro: Paz e Terra, 1978. 
MELO, Ricardo Henrique Vieira de et al. Roda de conversa: uma articulação solidária entre ensino, serviço e comunidade. Revista Brasileira de Educação Médica, Rio de Janeiro, v. 40, n. 2, p. 301-309, abr./jun. 2016.

PORTELLI, Alessandro. O que faz a história oral diferente. Projeto História, São Paulo, v. 14 , p. 25-39, fev. 1997.

UNIFESSPA - UNIVERSIDADE FEDERAL DO SUL E SUDESTE DO PARÁ. Programa de Acolhimento Estudantil \& Diversidade Indígenas e quilombolas na Unifesspa. Pesquisa Diagnóstico. Marabá, 2016.

\section{Fontes orais}

Aluna do Curso de Direito. [set. 2016]. Entrevistador: Flávia Marinho Lisbôa. Bom Jesus do Tocantins, PA, set. 2016.

Aluna do Curso de Educação do Campo. [out. 2017]. Entrevistador: Flávia Marinho Lisbôa. Bom Jesus do Tocantins, PA, out. 2017.

Aluno do Curso de Economia. [set. 2016]. Entrevistador: Flávia Marinho Lisbôa. Bom Jesus do Tocantins, PA, set. 2016.

Aluno do Curso de Geografia. [set. 2016]. Entrevistador: Flávia Marinho Lisbôa. Bom Jesus do Tocantins, PA, set. 2016.

Aluno do Curso de Pedagogia. [out. 2017]. Entrevistador: Flávia Marinho Lisbôa. Bom Jesus do Tocantins, PA, out. 2017.

Resumo: Este trabalho recupera parte do capítulo da metodologia de pesquisa de doutorado $\mathrm{da}$ autora, que adotou a "roda de conversa" como principal metodologia para acesso às narrativas de estudantes indígenas Gaviáo dos grupos Parkatêjê, Akrátikatêjê e Kyikatjê a respeito de suas vivências na Universidade Federal do Sul e Sudeste do Pará (Unifesspa). $\mathrm{O}$ intuito da pesquisa foi compreender as implicaçóes para a permanência desses alunos na universidade e a roda de conversa surgiu como a alternativa metodológica mais pertinente. Tal metodologia viabilizou não só a pesquisa, mas também se afirmou como uma ferramenta importante para reflexão e construção política da forma-sujeito dos alunos. Nas vivências partilhadas foi possível perceber a narrativa comum que eles partilhavam sobre as experiências do racismo institucional na educação superior no Brasil, denunciando a homogeneidade acadêmica, que materializa a colonialidade da sociedade contemporânea como um todo.

Palavras-chave: Amazônia. Indígenas. Universidade. 
Dialogue circle: methodology in the production of narratives about permanence at the university

Abstract: This article recovers part of the chapter from author's doctorate degree thesis related to research's methodology, that adopted "dialogue circle" as the main methodology to access the narratives of the indigenous Gavião students, that belong to the groups Parkatejê, Akrátikatejê and Kyikatejê, related to their experiences in the Federal University from Parás South and Southeast (Unifesspa). The research's objective was comprehend the implications to permanence of these students in the university. In this sense, the dialogue circle emerged as a most relevant methodological alternative. Such methodology enabled not only the research, but also asserted itself as a important tool to political reflection and construction of the student's form-subject. In shared experiences it was possible to perceive the student's common narrative about their institutional racism experiences in the Brazil's college education, denoucing the academic homogeneity that materializes the contemporaneous society's coloniality as a whole.

Keywords: Amazon. Indigenous people. University.

Recebido em 26/03/20

Aprovado em 25/05/20 